\title{
Transient and Quasi-Steady Thermal Behaviour of a Building Envelope due to Retrofitted Cavity Wall and Ceiling Insulation
}

\author{
Aimee Byrne \\ Technological University Dublin, aimee.byrne@tudublin.ie \\ Gerard Byrne \\ $T C D$ \\ Anna Davies \\ $T C D$
}

See next page for additional authors

Follow this and additional works at: https://arrow.tudublin.ie/engschcivart

Part of the Energy Systems Commons, Environmental Engineering Commons, Heat Transfer, Combustion Commons, Other Civil and Environmental Engineering Commons, Other Materials Science and Engineering Commons, and the Structural Engineering Commons

\section{Recommended Citation}

Byrne, A., Byrne, G., Davies, A. and Robinson, A. J. (2013) 'Transient and quasi-steady thermal behaviour of a building envelope due to retrofitted cavity wall and ceiling insulation', Energy and Buildings, 61(1), 356-365. doi;10.1016/j.enbuild.2013.02.044

This Article is brought to you for free and open access by the School of Civil and Structural Engineering at ARROW@TU Dublin. It has been accepted for inclusion in Articles by an authorized administrator of ARROW@TU Dublin. For more information, please contact arrow.admin@tudublin.ie, aisling.coyne@tudublin.ie, gerard.connolly@tudublin.ie.

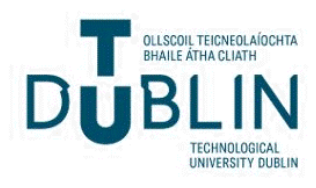


Authors

Aimee Byrne, Gerard Byrne, Anna Davies, and Anthony Robinson

This article is available at ARROW@TU Dublin: https://arrow.tudublin.ie/engschcivart/77 


\title{
Transient and quasi-steady thermal behaviour of a building envelope due to retrofitted cavity wall and ceiling insulation
}

Aimee Byrne ${ }^{a, *}$, Gerard Byrne ${ }^{b}$, Anna Davies ${ }^{c}$, Anthony James Robinson ${ }^{b}$

\author{
a Department of Civil, Structural and Environmental Engineering, Trinity College Dublin, \\ Ireland \\ $\mathrm{b}$ Department of Mechanical and Manufacturing Engineering, Trinity College Dublin, Ireland \\ c Department of Geography, Trinity College Dublin, Ireland
}

Published in:

Energy and Buildings 61 (2013) 356-365

\section{Keywords:}

Retrofit

Energy efficiency

Insulation

Heat flux

Heat flow

Thermal resistance

In situ

\begin{abstract}
A B S T R A C T
Accurate understanding of the thermal behaviour of building components is essential for predicting heating or cooling needs and facilitates the implementation of more successful energy saving strategies and retrofits. This paper focuses on a specific measure commonly introduced through the residential energy efficiency retrofit programmes in Ireland-insulation. Traditionally, assessments of the performance of building envelopes have been based on assumed thermal resistances of the materials involved, laboratory tests and computer modelling. The aim of the present work is to investigate the in situ thermal behaviour of a case study building and its components under transient and quasi-steady environmental conditions, comparing data before and after the fixing of cavity wall and ceiling insulation. The paper concludes by proposing that predicted values of heat loss using standardised assumed material properties of the existing structure do not reflect the actual values achieved in situ for this test case. These values greatly overestimated the impact of the retrofitted insulation on heat loss through the ceiling and wall.
\end{abstract}

\section{Introduction}

\subsection{Background}

The EU has set itself the objective of achieving 20\% primary energy savings in 2020 [1]. Energy use in residential and commercial buildings is responsible for approximately $40 \%$ of the EU's total final energy consumption and $36 \%$ of its total $\mathrm{CO}_{2}$ emissions [2]. This sector has a potential to save $11 \%$ total energy in the EU by 2020 . The European Commission's assessment of National Energy Efficiency Action Plans (NEEAPs) found that residential building renovation is the focal point of most national plans [2]. However, there was at most, sporadic indication of savings estimated along with very limited degrees of detail on assumptions made in approximating savings from different measures.

Cavity and roof insulation are the two most common grants taken up by occupants under the Better Energy Homes Scheme highlighted in the NEEAP for Ireland [3]. Thermal insulation is used to resist the flow of heat and so raises the thermal impedance of the element to which it is attached. Thermal resistance or $R$ value is a measure of the insulating ability of the material layer

\footnotetext{
* Corresponding author. Tel.: +353 876674185 .

E-mail address: aimee.byrne@dit.ie (A. Byrne).
}

or composite structure. A higher $R$-value indicates a more effective insulator which can reduce heating needs and costs as well as improve the thermal comfort of the internal environment.

The industry method for estimating the potential thermal changes due to insulation is by using nominal $R$ - and $U$-values (the inverse of $R$ ) or other tabulated properties. Design guides and handbooks only provide the design values for thermal properties which are based on idealised steady state conditions. Generally, estimates for thermal properties tend to underestimate the insulating ability of walls compared to in situ findings [4], with values for ceilings showing particularly poor agreement with in situ values. Density is usually cited as the key factor influencing the thermal resistance of insulation [5] however, due to the manufacturing process; density and other properties are often unknown. Even if the value is known for that material type, uncertainty is still present due to uncontrollable factors in processing and the limited accuracy of measurement. Furthermore, the building structure surrounding the insulation is often made of heavier materials such as concrete and masonry which have variable constituents, meaning that estimates of their thermal conductivities can only ever be approximate [6].

Site influencing factors such as temperature and moisture content impact on the practical thermal resistance and behaviour of the wall unit $[7,8]$. A further uncertainty is introduced in the specific case of cavity walls. The movement of air and heat flow in such a 


\begin{tabular}{|ll|}
\hline \multicolumn{2}{|c|}{ Nomenclature of units } \\
$C$ & heat capacity $(\mathrm{J} / \mathrm{K})$ \\
$C$ & specific heat capacity $(\mathrm{J} / \mathrm{kg} \mathrm{K})$ \\
$H C / A$ & heat capacity per unit area $\left(\mathrm{J} / \mathrm{K} \mathrm{m}^{2}\right)$ \\
$k$ & thermal conductivity $(\mathrm{W} / \mathrm{m} \mathrm{K})$ \\
$m$ & mass $(\mathrm{kg})$ \\
$q_{x}$ & heat transfer rate, or heat flux $\left(\mathrm{W} / \mathrm{m}^{2}\right)$ \\
$R$ & thermal resistance of the total structural element \\
& being examined $\left(\mathrm{m}^{2} \mathrm{~K} / \mathrm{W}\right)$ \\
$R_{s e}$ & thermal resistance of the external surface $\left(\mathrm{m}^{2} \mathrm{~K} / \mathrm{W}\right)$ \\
$R_{s i}$ & thermal resistance of the internal surface $\left(\mathrm{m}^{2} \mathrm{~K} / \mathrm{W}\right)$ \\
$T_{S}$ & surface temperature $(\mathrm{K})$ \\
$T_{s e}$ & external surface temperature $(\mathrm{K})$ \\
$T_{s i}$ & internal surface temperature $(\mathrm{K})$ \\
$T_{s u r}$ & temperature of the surroundings $(\mathrm{K})$ \\
$T_{\infty}$ & ambient air temperature $(\mathrm{K})$ \\
$\delta$ & wall sublayer thickness $(\mathrm{m})$ \\
$\rho$ & density $\left(\mathrm{kg} / \mathrm{m}^{3}\right)$ \\
\hline
\end{tabular}

cavity is quite complex especially for larger cavities combining conduction, convection and radiation [9]. Air tightness [10] and cavity depth [11] affects the wall units thermal performance along with other unknown in situ aspects such as ground surface temperature at the base of the cavity, type and quality of sealing detail at the top of the cavity and general workmanship of the walls. Attempts have previously been made to examine the thermal behaviour of buildings in situ. Due to the exposed nature of the test, certain conditions cannot be controlled as in a laboratory or in computer models.

There are generally two separate approaches taken in examining the effectiveness of the building envelope in situ. The first methodology involves monitoring the internal conditions and energy usage [12-14]. These studies tend to focus on the building-in-use data $[12,15,16]$ and testing tends to involve a number of retrofit procedures not just insulation. However, this test methodology does not quantify the behaviour of the building with and without insulation under standardised conditions so that the true benefit of individual retrofit measures can be quantified. The second methodology involves using a heat flux metre and surface temperature sensors to monitor the heat transfer through a specific building element being examined [17-19]. The temperature difference measured across the structure indicates the thermal resistance of the element [20]. The higher the temperature difference across the wall, the higher the accuracy of the in situ methods and a temperature difference below $10^{\circ} \mathrm{C}$ is not considered sufficiently accurate [21].

Because of the limited examples of in situ testing, and indeed ones relevant to this research, a number of studies using simulations have served to postulate the thermal behaviour of building envelopes with and without insulation. However, models have been shown to underestimated peak heat fluxes by $17 \%$ on average and the cumulative difference between fluxes by 9.6\% [22]. Furthermore, a lag of up to an hour was observed between predicted and measured values. Medina [22] believed that a discrepancy between simulated values for heat flux and actual values was mainly attributed to the heat storage effect of the wall frame and that elements within the wall were not accounted for along with the question of what environmental conditions to simulate. The reliability of simulation has been shown to become even more spurious in the case of composite walls [23]. Moreover, comparisons of the same wall with and without insulation showing the true value of the retrofit could not be found.

The following sections examine the current understanding of the behaviour of walls and insulation layers as based on theoretical simulations and calculations. It is these proposed performances of wall masses with and without insulation which form the basis of the in situ methodology designed for this study. The theories formulated through simulations in previous studies are then compared with actual findings in situ in Section 3, quantifying the reliability of their deductions.

\subsection{Thermal time constant}

The thermal time constant is used to compare the dynamic response of a structure to a change in the internal environment from a position of equilibrium. It is a parameter reflecting how rapidly the wall responds to a step change in air temperature, i.e. how long it takes for the heat flowing through the wall to become a constant rate. Previous research conducted by Tsilingiris [24] using simulations, found that there is a higher thermal time constant on the side of the wall closest to the materials of higher thermal mass. Thermal mass, or heat capacity, in Eq. (1) represents the structure's capability in storing heat; per unit area this becomes Eq. (2). For composite structures, $i$ represents each homogeneous layer with $n$ homogeneous layers in the system.

$$
\begin{aligned}
& C=\sum_{i=1}^{n} m_{i} c_{i} \\
& \mathrm{HCA}=\frac{C}{A}=\sum_{i=1}^{n} \rho_{i} c_{i} \delta_{i}
\end{aligned}
$$

While the total heat capacity of the composite wall is the same no matter which direction heat is flowing through it, heat capacity is closely related to the wall's thermal time constant [25]. A low thermal time constant of heat flow from the interior of the wall to the exterior (which can be achieved by placing insulation internally) has been shown to be beneficial in intermittently heated/cooled and scarcely occupied spaces [24,26]. Conversely, positioning the insulation externally has been shown to result in the minimum annual heating and cooling energy demand compared with other positions [27]. Simulated evidence has shown that it is more beneficial to locate insulation internally if the interior is so intermittently heated that the wall returns to equilibrium with the external environment and must then go through a transient state as it is heated up again each time. But for continuously lived in homes, the walls do not have adequate time to return to such cool levels and so external insulation proves to be more advantageous. This is due to its moderating effect on the internal space and its capability to acting as a thermal storage medium.

As discussed, while heat capacity strongly influences both transient heat flow and the time it takes to reach steady state, it does not have any impact on the steady or quasi-steady state heat flow behaviour [25]. Under realistic winter and summer conditions, the average heat flux is not dependant on heat capacity of the wall but on its $R$ - and $U$-values. It is therefore expected that most benefit of installing insulation (of high $R$-value, but low thermal mass) should be observed during steady state and in-use heating conditions of the used building.

\subsection{R-value and constant heat flow}

Thermal resistance values taken from standardised material values in industry are based on area, thickness and thermal conductivity or in research by testing prototype walls in laboratory conditions [28-30]. Under the correct environmental conditions it has been proposed that evaluating $R$-value of buildings by direct measurement using a heat flux sensor and surface temperature 
sensors is more useful than using standardised $R$-values of the various layers of the composite system [21].

$R=\frac{\delta}{k A}$

Effective thermal conductivity of composite materials is related to the rate of heat flow at steady state and the temperature difference across the material. Tabulated values of thermal conductivity used to determine thermal resistance of existing and new structures include Part L of the Building Regulations [31] or CIBSE Guide A [32]. In situ, steady environmental conditions can be difficult to achieve. When heating the internal environment, the point at which steady state is achieved can itself be difficult to identify. For laboratory testing, it has been determined as the point at which deviations between successive temperatures over a period of $4 \mathrm{~h}$ have diminished to less than $0.5^{\circ} \mathrm{C}$ [11], i.e. when the thermal results begin to vary randomly rather than monotonically. According to Baker [33], under typical in use conditions and starting from equilibrium, a period of at least a week is required to attain $U$-values (and therefore $R$-values) within $5 \%$ of the final 27 day value. However, this stipulation is for fluctuating indoor temperatures of a used building and so the required time for the study presented in this paper is greatly reduced. Baker then uses the averaging method (Eq. (4)) as outlined in ISO 9869 [34]. Using this method, thermal resistance can be calculated from surface to surface. The standard specifies that a minimum of $72 \mathrm{~h}$ of recording is needed if the temperature is stable around the heat flow metre.

$R=\frac{\sum_{j=1}^{n}\left(T_{s i j}-T_{s e j}\right)}{\sum_{j=1}^{n} q_{j}}$

Conversely, Al-Sanea et al. [35] proposed separating $R$-value as it is conventionally used from dynamic $R$-value. Under their definition, dynamic $R$-value is summed per day using Eq. (4) to find variations in the thermal resistance of walls over different seasonal periods. This means that the normal $R$-value of a given wall or other building envelope structure remains the same while its dynamic $R$-value varies depending on internal and external environments. This is particularly important when designing elements for varying conditions as is the case with building envelopes.

\subsection{Heat retention}

For an uninsulated wall, it is understood that materials can continually transfer heat from the warmer side of the shell and convey it to the cooler side. However, if the structure is insulated a large proportion of this stored heat within the wall can return to the internal environment. The implications of this ability to absorb, store and release heat back into the interior include moderation of the internal temperature and reduction in heating costs [36]. Furthermore, the thermal mass of the wall creates a damping effect on internal temperature fluctuations and filling a wall cavity has been shown to greatly enhance the damping effects of the wall [10].

\subsection{Summary}

This paper presents the findings of a thermally monitored vacant house which was heated from an initial condition where it is in thermal equilibrium with the ambient surroundings. It was maintained at a high temperature for approximately one week and allowed to cool. The study was then repeated after insulation was pumped into the wall cavities and laid over the ceiling in order to define the immediate and achievable benefits of the procedure. The heating up phase of this study tests the theory of thermal time constants in situ which has already been shown to be relevant in previous simulations and discussed in this section. Specifically, it tests the

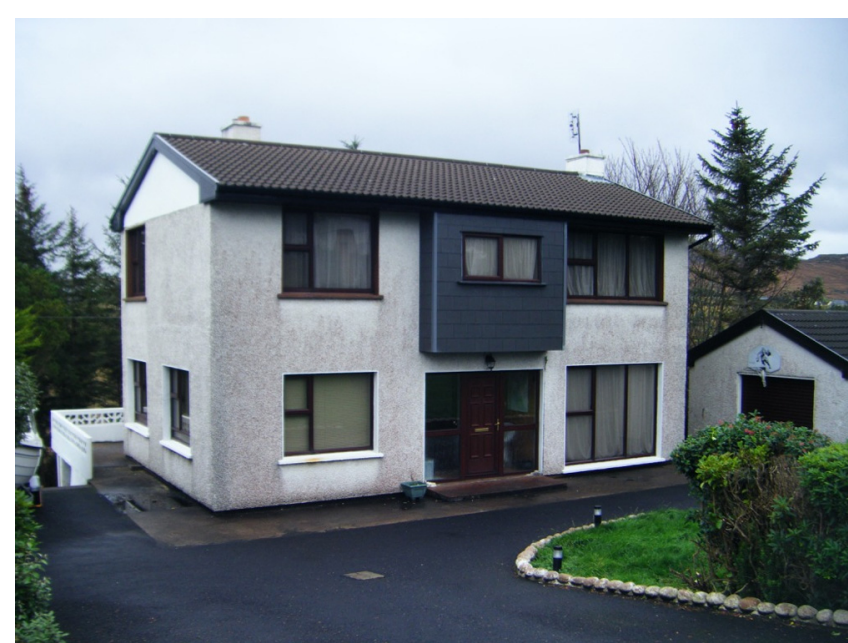

Fig. 1. View of case study building from the north-west.

finding that the introduction of cavity insulation increases the thermal time constant of the wall [24]. Data from the quasi steady heat flow phase of the experiment is used to compare dynamic $R$-values and heat flows for the insulated and uninsulated building envelope. This data is also used to compare the damping ability of the building shell before and after retrofit. The third phase of the study involves examining data after the heat is turned off, giving an indication of the ability of the building to retain heat. It also shows the ability of the walls to resubmit their stored heat back into the internal space. By comparing the cooling down heat transfer and the heating phase heat transfer for the same system, the effectiveness of the building envelope as an insulator and heat store can be examined. This study is not focused on wall and ceiling types, but on the difference in thermal behaviour achieved due to the introduction of insulation. Therefore, the unknown nature of workmanship, quality and composition of the existing structural elements are not of importance to the analysis as they remain the same before and after retrofit. The data is compared using the same time period and heat energy input showing changes in internal temperatures, degree of influence of the external environment, time for the internal environment to reach steady state, quasi-steady state heat flow through the wall along with heat retention of the building when heat is turned off.

\section{Case study}

\subsection{Case study building}

The case study building is located near the north-west coast of Ireland experiencing a temperate oceanic maritime climate. Fluctuations in external temperature of between 4 and $16^{\circ} \mathrm{C}$ were experienced over the monitored period and are typical of October/November and April/May temperatures for the region [37]. The local conditions while testing were mainly wet with variable wind direction and speed. The house remained vacant for the monitored period so as to reduce additional behavioural variables and to ensure that no heat was lost through temporary opening of doors or windows.

The building is a two storey detached family home facing west and built in the 1970s (Fig. 1). The external walls are of cement block construction, separated by a $100 \mathrm{~mm}$ uninsulated cavity, with plaster to the internal face and render to the external face. Cavity walls became the standard construction for external walls in North Western Europe after World War II due to their water tightness with the cavity acting as a capillary break [10]. Regulations to reduce heating 


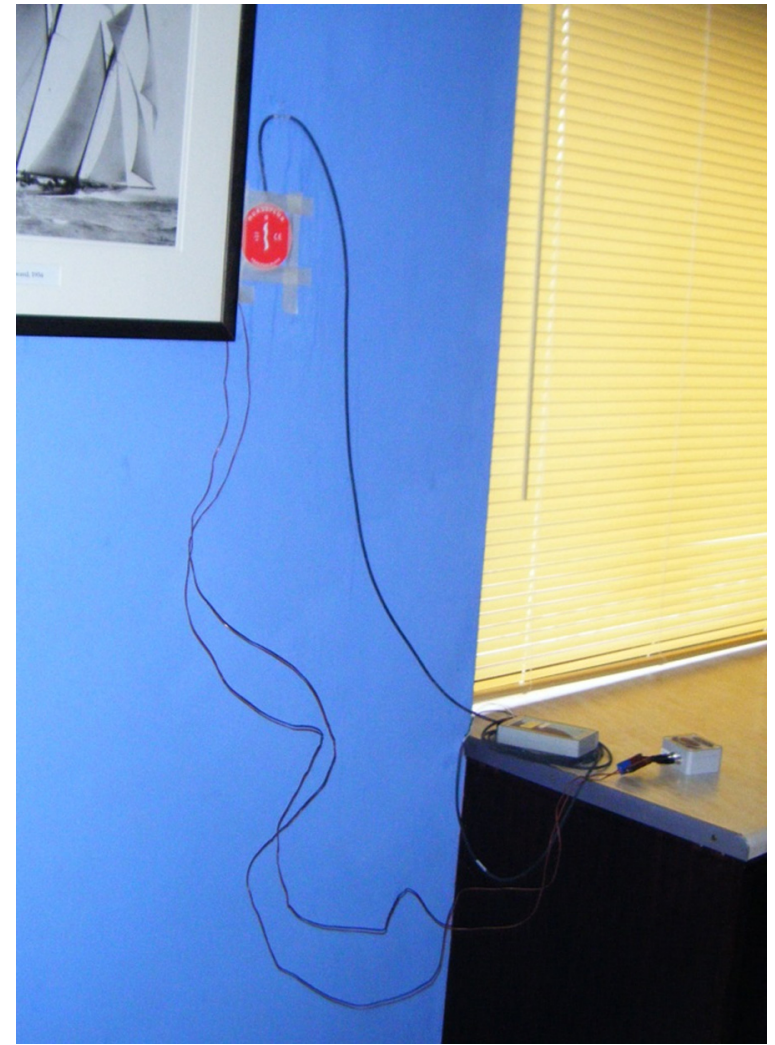

Fig. 2. Position of wall heat flux metre and internal surface temperature sensor.

demand in buildings were introduced in European countries from the 1970s, but many countries including Ireland only introduced them in the 1990s [38]. This has resulted in a high potential to save energy in this sector through retrofitting of thermal insulation. The loft is insulated with its original minimal fibreglass insulation blankets, including many areas of no insulation.

Over the monitored period the building was retrofitted with pumped polystyrene bead insulation in the external wall cavity and thick glass wool insulation layers in the loft using the standard methods allowed under the grant scheme. Loft insulation also surrounded water tanks and piping to prevent freezing of the contained water during cold periods.

\subsection{Monitoring}

Monitoring of the building occurred for a two week period before and two after retrofit during October/November 2011. Each of these two week periods consisted of the house beginning in equilibrium with the external and internal environments. For phase one, the central heating was turned on to its full power until quasisteady state heat flow through the building envelope was observed. Phase two involved leaving the house in this state of heat flow for a number of days with the central heating remaining at a constant rate. For phase three, the heating was then turned off and the house allowed to return to its cold state. The modifications to its thermal behaviour due to the retrofitted insulation could then be compared under all three conditions.

A Hukseflux HFP01 heat flux sensor with a LI19 datalogger was used to measure the heat flow through a location on a north facing wall and away from windows or sources of heating, cooling or solar gains (Fig. 2). A north facing wall ensured that no direct sunlight could influence heat flow from the outside as solar gains would increase the temperature of the external surface and surrounding air. Furthermore, all windows and other openings were covered so as to limit the influence of solar gains on internal temperatures. The area on the wall was chosen by placing the heat flux sensor at a number of locations to pinpoint a position which was representative of general heat flow through the entire wall. Thermal imaging was used to certify further that the location chosen was representative of overall wall conditions pre and post retrofit. Thermal paste was used to maintain even contact with the wall. The sensor itself has been factory calibrated within the limits of $\pm 0.1 \%$. Internal and external surface temperatures were also recorded at this location using thermocouples and Logbox dataloggers. The external surface thermocouple is placed within a small drilled hole in the outermost layer of the wall. A similar setup was used to measure heat flowing between the house and attic through the ceiling structure. Here the heat flux sensor was placed on the underside of the ceiling and the surface temperature sensors placed at the same location on the ceiling and the attic floor. Measurements were logged every $3 \mathrm{~min}$ for heat flux and every $15 \mathrm{~min}$ for temperature.

Internal room conditions were recorded using Logbox dataloggers. Air temperature was monitored every $15 \mathrm{~min}$ in the living room, the kitchen, three of the four bedrooms, stairs, and outside the north and south walls of the house.

Fuel consumption for heating over the period was estimated using the fuel storage tank diameter and level reading. A temperature sensor was attached to the flue of the boiler to record firing cycles every $15 \mathrm{~s}$ and sensors attached to the inlet and outlet flow to the radiator circuit to record the temperature difference across them every $15 \mathrm{~min}$. These values give an indication of the amount of work the heating system is doing to ensure that there was approximately the same amount of heat energy input into the building for both pre- and post-retrofit testing periods.

Thermal images were also taken of the ceiling and exterior of the building to identify locations where excessive heat is being lost (or "thermal bridges"). In a poor insulator, heat sources can be readily located from the outside, such as radiators or heated flues as much of this heat is escaping through the building envelope.

\section{Results}

\subsection{Variables}

As this is an in situ study, errors were limited to within what was achievable in the field. As the external climatic conditions could not be controlled, ambient temperatures were on average $0.9{ }^{\circ} \mathrm{C}$ higher during pre-retrofit testing compared to post-retrofit. If anything, this would lead to slightly conservative estimates of potential savings in heat and energy due to insulation. The boiler ignition times and fuel consumption over the two analysis periods were not significantly different meaning that heat energy input was the controlled factor in comparing the two test periods. The same sensors were positioned in the same locations for the pre- and post-case so that errors in measurements are the same for both sets. The postretrofit test began one week after retrofit to ensure similar climactic conditions for both tests.

\subsection{Pre-retrofit}

\subsubsection{External walls}

Testing began with the internal temperature of the building at the same temperature as the outside. The building and its envelope were considered to be in thermal equilibrium with its surroundings. Under these conditions, after the heating was turned on to full power, the time it took for heat flow to become quasi-steady was found to be approximately $20-34 \mathrm{~h}$ for those conditions (heat up phase in Fig. 3). It is at this point that the heating phase is complete and heat flux begins to fluctuate. Under quasi-steady heat supply 


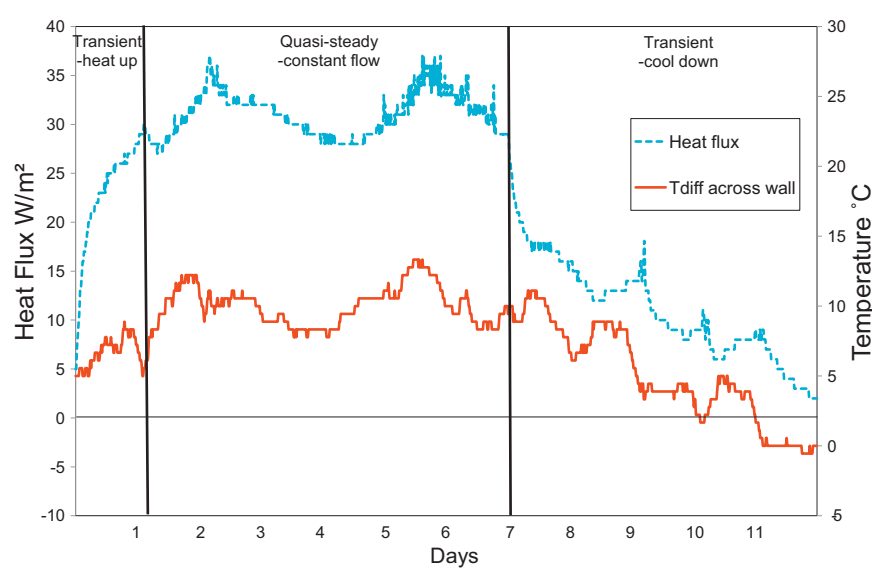

Fig. 3. Heat flux and temperature difference across the uninsulated wall during heating up, quasi-steady heat loss and cooling down phases.

of phase two, the average heat flux of the wall was $31.3 \mathrm{~W} / \mathrm{m}^{2}$ with a standard deviation of 2.21. As is visible in Fig. 3 the heat flux mimics the pattern of temperature difference across the wall, displaying the degree of influence of the external environment on heat flow. The average heat flux value was taken over a period which is a multiple of $24 \mathrm{~h}$ in order to counteract the influence of daily fluctuations.

Thermal imaging was used during the quasi-steady heat loss phase to identify locations and severity of thermal bridging in the building and compare images of before and after the installation of insulation. Examining Fig. 6, the locations of the radiators under the two first floor windows show high temperatures on the outside of the wall. This indicates that a large portion of the radiator heat is being lost at these locations. Other bridging points were identified at joints of the wall with the attic and the bay above the front door. As seen in Fig. 4 the wall surface temperature internally remains on average $4.7^{\circ} \mathrm{C}$ lower than the internal air temperature. This, along with the similar, albeit damped, pattern of peaks and troughs to the external environment, shows the high degree of influence that the external weather conditions have on the enclosed space.

As discussed in Section 1.3, steady state conditions are used to calculate the thermal resistance of building materials and envelopes. Using the averaging method of Eq. (4), the instantaneous thermal resistance values for the wall are displayed in Fig. 5 for heating and quasi-steady heat flow phases. The achievable thermal resistance under steady boundary conditions was $0.372 \mathrm{~m}^{2} \mathrm{~K} / \mathrm{W}$ with a low level of deviation of 0.041 . The thermal resistance of the full wall system is higher due to the inclusion of surface resistances

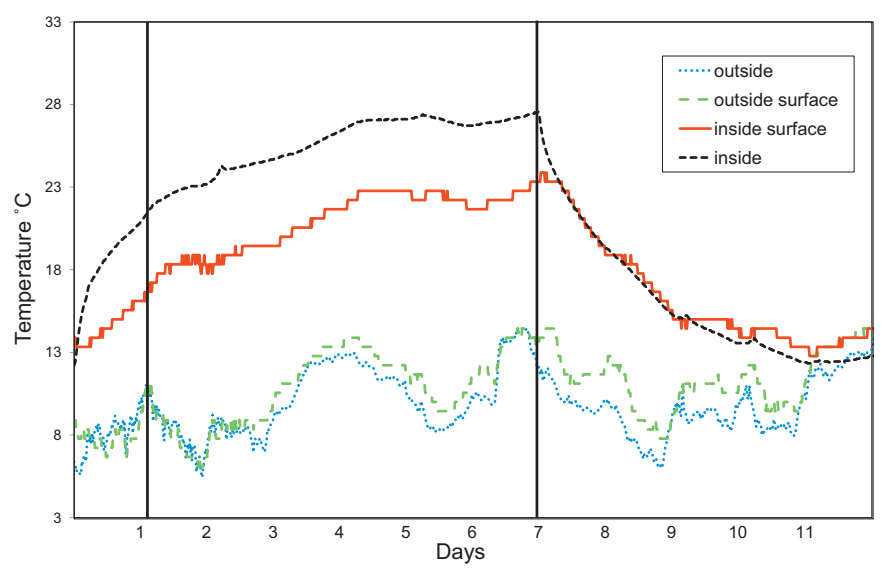

Fig. 4. Surface and air temperatures around the uninsulated wall.

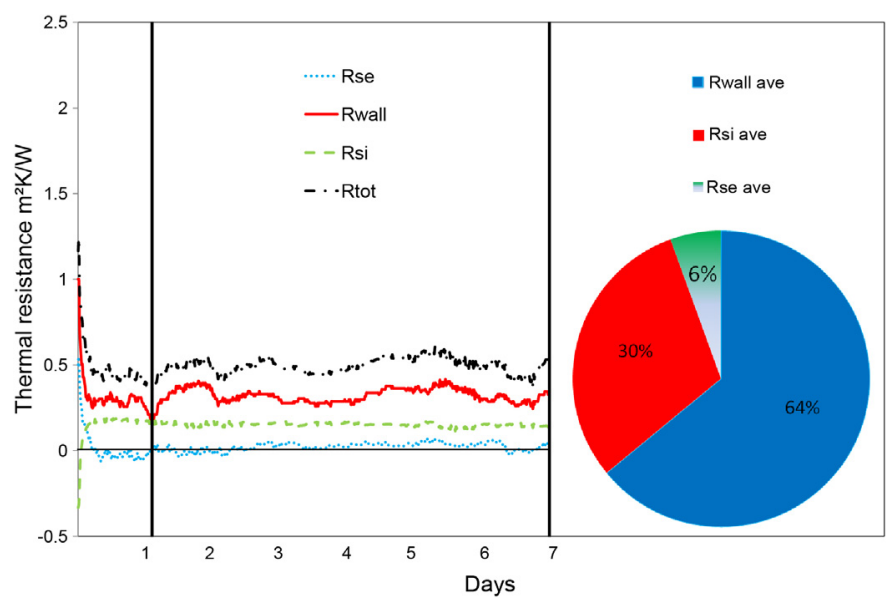

Fig. 5. Total thermal resistance of the uninsulated wall system with breakdown of resistance of each layer.

(Eq. (5)). By assuming that temperature of the medium $\left(T_{\infty}\right)$ used to calculate convective surface resistance, $\left(T_{\infty}-T_{s}\right) / q$, is the same as the temperature of the surroundings $\left(T_{\text {sur }}\right)$ used to calculate radiation surface resistances, $\left(\left(T_{s}-T_{\text {sur }}\right) / q\right)$, the effective surface resistances can be calculated using the air and surface temperature values and are displayed in the pie chart in Fig. 5. The wall mass occupies the vast majority of the overall thermal resistance, however, the internal surface resistance is still considerable. Here it is likely that internal radiation resistance to the wall is negligible as its position meant that it was not "seen" by any hot bodies. Externally the radiation resistance is presumed to be minimal compared to the high convective resistances experienced in that highly exposed location. According to ISO 6946 [39] $R_{s i}$ is usually taken as $0.13 \mathrm{~m}^{2} \mathrm{~K} / \mathrm{W}$ in the absence of information on boundary conditions for horizontal surfaces. The average value for this study was found to be $0.15 \mathrm{~m}^{2} \mathrm{~K} / \mathrm{W}$. $R_{\text {se }}$ is taken as $0.04 \mathrm{~m}^{2} \mathrm{~K} / \mathrm{W}$, but was found to be $0.02 \mathrm{~m}^{2} \mathrm{~K} / \mathrm{W}$ in this experiment. Neither values found differed significantly from the ISO 6946 standard values which are based on combined radiation and convection at the surface.

$R_{t o t}=R_{s i}+R+R_{s e}$

Data after the heat is turned off showed that the wall continued to draw heat from the internal space over the following five days, albeit at a continuously lowering rate (cool down phase Fig. 3).

\subsubsection{Ceiling}

The time it took for the ceiling to reach quasi-steady heat flow was much less than for the walls at $5.5 \mathrm{~h}$ (see Fig. 7). This shorter time is attributed to the low thermal mass and therefore low heat capacity of the single plaster layer of the ceiling. During phase two the ceiling showed an average heat flux of $44.2 \mathrm{~W} / \mathrm{m}^{2}$ for a constant heat energy input and high standard deviation of 3.81. When comparing Fig. 7 with the thermal behaviour of the wall in Fig. 3 it can be seen that the heat flux is higher through the ceiling, while the temperature difference across the ceiling remains similar to that of the wall. Using Eq. (4) this difference in heat flux can therefore be assumed to be due to the much lower thermal resistance of the ceiling.

Internally, the ceiling shows a number of areas completely lacking in insulation. Fig. 10 displays an area above the main bedroom where thermal bridging was extensive due to large areas of missing insulation. Similar cold spots were identified in every room on the upper floor. This led to the very gradual change in temperature at the various ceiling layers shown in Fig. 8. It is also observed in this figure that the troughs and peaks in ambient temperature 


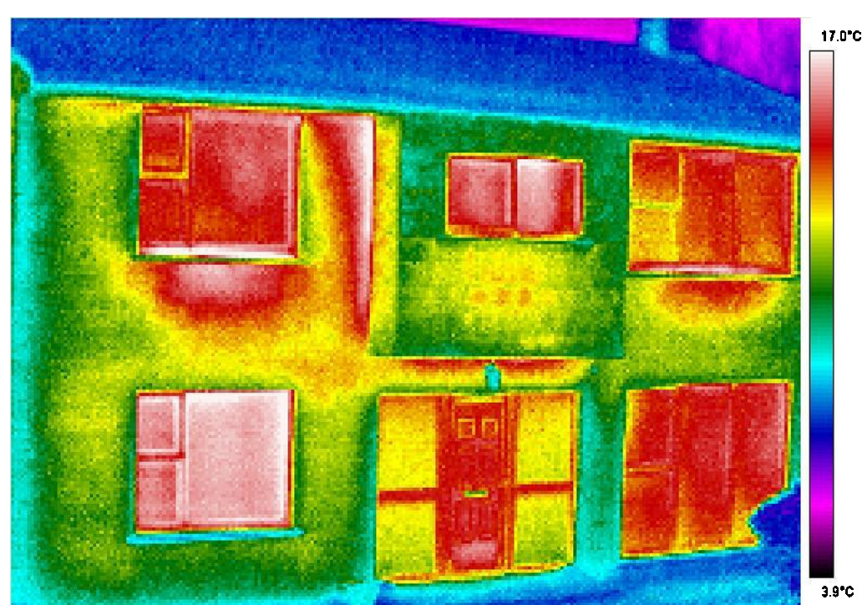

Fig. 6. Front face of building pre-retrofit.

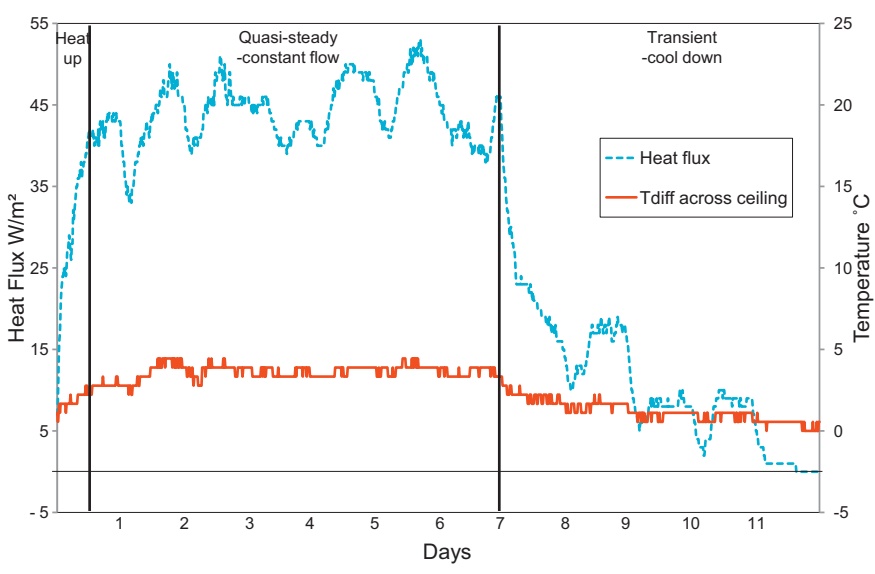

Fig. 7. Heat flux through the uninsulated ceiling during heating up, quasi-steady heat loss and cooling down phases.

become more and more diminished, yet still identifiable, at each ceiling layer.

Using the averaging method, the thermal resistance of the ceiling was found to be $0.082 \mathrm{~m}^{2} \mathrm{~K} / \mathrm{W}$ at the measurement location (Fig. 9). It displayed a standard deviation of 0.007 which is significantly lower than the fluctuations for heat flux during the same period. Using Eq. (4) and examining the fluctuations in external temperature (Fig. 8) with heat flux fluctuation patterns of Fig. 7, it

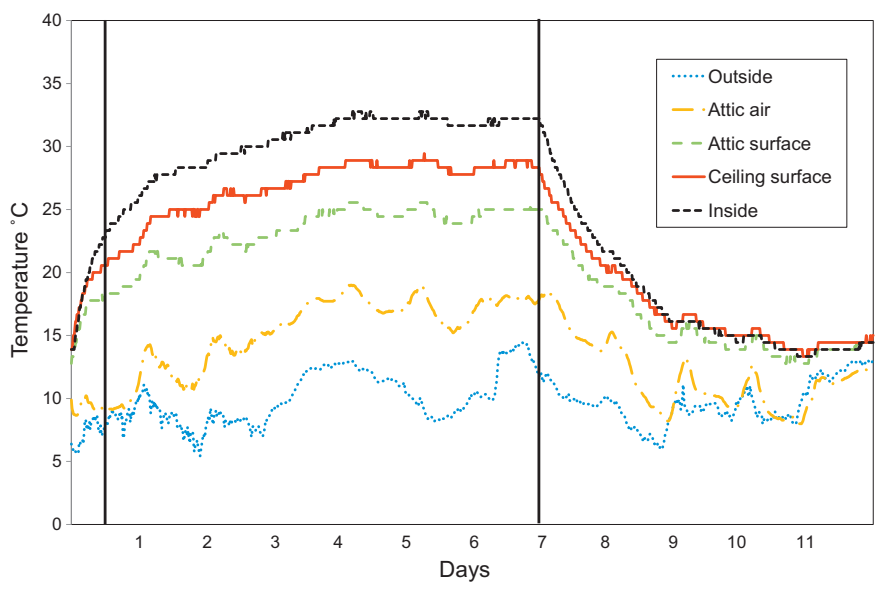

Fig. 8. Surface and air temperatures around the uninsulated ceiling. is shown that the heat flow through the ceiling is highly dependent on the temperature difference across it as is expected. Changes in external temperatures are followed by a short delay before similar fluctuations are observed in the heat flow across the ceiling. $R_{s e}$ accounts for half of the overall thermal resistance of the system with $R_{\text {ceiling }}$ and $R_{s i}$ sharing the remaining half. $R_{s e}$ was found to be $0.173 \mathrm{~m}^{2} \mathrm{~K} / \mathrm{W}$ compared to standard $0.1 \mathrm{~m}^{2} \mathrm{~K} / \mathrm{W}$ for upward heat flow into an unheated space [37]. Because of the high temperature of the attic floor layer and attic space the radiation resistance is assumed to be very high. Unlike for the wall, the high temperature difference in Eq. (4) between the external surface and the external air seen in Fig. 8 leads to higher heat flow. The attic surface itself being of high temperature due to the low thermal resistance of the thin ceiling layer. $R_{s i}$ was found to be $0.08 \mathrm{~m}^{2} \mathrm{~K} / \mathrm{W}$ compared to $0.1 \mathrm{~m}^{2} \mathrm{~K} / \mathrm{W}$ taken in the standard, a low value as the internal surface and air temperatures are closer.

For phase three of the test, when the heating system is turned off the heat flux to the ceiling returns to zero more quickly than for the wall by a number of days (Fig. 7 compared to Fig. 3). This factor, which is presumed to be due to the considerable difference in thermal mass, is consistent with the heating up phase results.

\subsection{Post-retrofit}

\subsubsection{External walls}

The heating up phase one took twice the amount of time as the pre case, at $76 \mathrm{~h}$, before the heat flux became steady once insulation was installed. As per previous studies using simulations, cavity insulation is known to cause an increase in the thermal time constant of the wall. Simulations under similar temperature differences show an approximate doubling of the value when comparing brick cavity walls without and with $40 \mathrm{~mm}$ insulation in the gap [24] and in comparing a $250 \mathrm{~mm}$ concrete wall to the same one with $50 \mathrm{~mm}$ of insulation in the middle [26]. From examining the different heat flux patterns in Fig. 11 versus Fig. 3, it is observed that by introducing insulation, heat is initially transferred from the internal space similar to the pre-case, however after a relatively short period of time the amount of heat being lost to the wall begins to decrease from its peak (unlike the pre-case). Due to the presence of insulation in the cavity, the path of heat flowing through the wall is blocked half way, to some extent, by the low conductivity insulation layer and encounters resistance to passing fully through the wall. By comparing Fig. 11 to Fig. 3 it is immediately obvious that the temperature difference across the wall greatly increases with the introduction of insulation. Furthermore by comparing Fig. 12 to Fig. 4 the pattern of the internal surface and air temperatures no longer show any similarity to the external temperature fluctuation pattern and have become much more uniform with each other. Because of this evident block to heat flow between the internal hot and external cold space, the inner leaf of block work then begins to heat up reaching its capacity of heat storage. Only once this capacity is reached does the heat flux reading reflect the amount of heat passing fully through the wall and not just being retained in the inner block work. This is evidenced further by examining the cooling down phase as discussed later in this section.

Thermal images show the reduction in thermal bridging and overall heat loss through the wall when comparing Figs. 6 and 13. It is evident that the internal temperature of the wall has become much more uniform post-retrofit. Heat leakage remains visible at joint locations, between the roof and wall, and around the more recently added bay window fitted above the front door, however they are less extensive and have become focused at the joint line. The positions of the radiators under the windows are almost unidentifiable.

Under steady state heat flow, the average heat flux to the wall reduced by $56 \%$ to $13.5 \mathrm{~W} / \mathrm{m}^{2}$ for a quasi-constant heat 


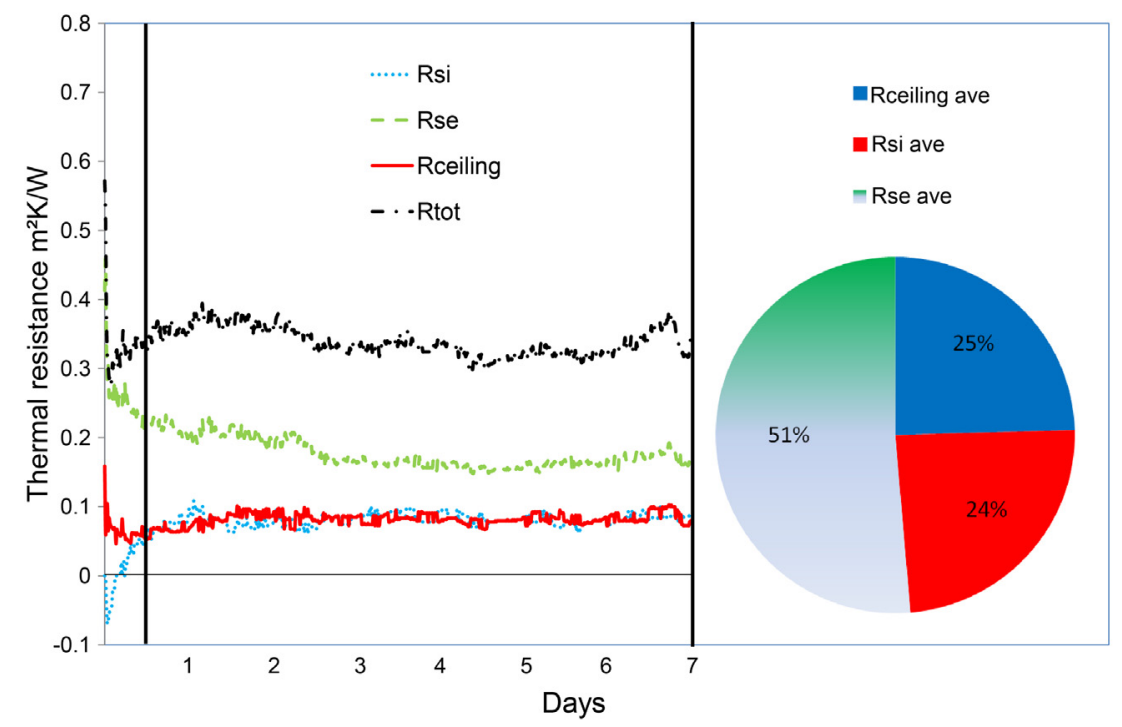

Fig. 9. Total thermal resistance of the uninsulated ceiling system with breakdown of resistance of each layer.

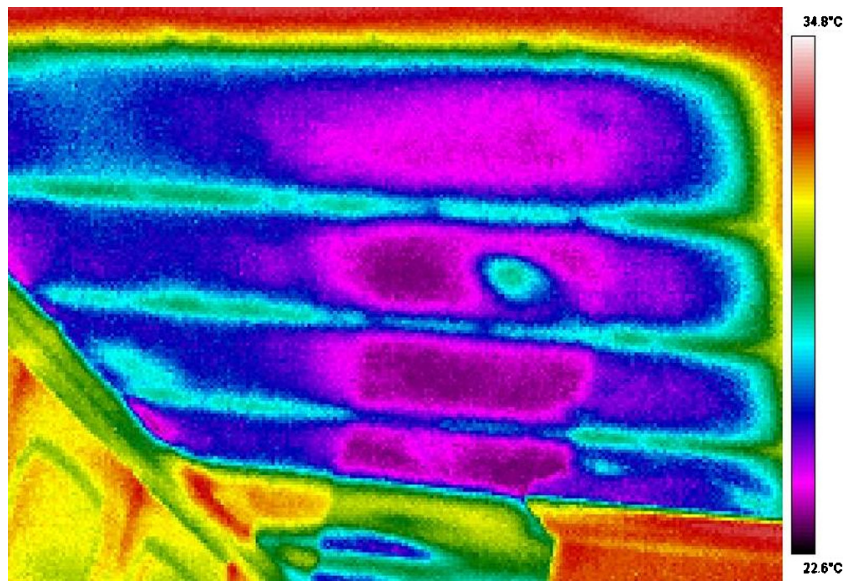

Fig. 10. Area lacking in ceiling insulation above the main bedroom pre-retrofit.

energy input. The standard deviation also reduced by $33 \%$ to 0.73 . Calculated $R$-values for the wall using internal and external air temperatures and ISO 6946 predict a heat flow reduction of $75.3 \%$ due to the retrofitted insulation, overestimating the actual change achieved. This is because calculated $R$-values greatly

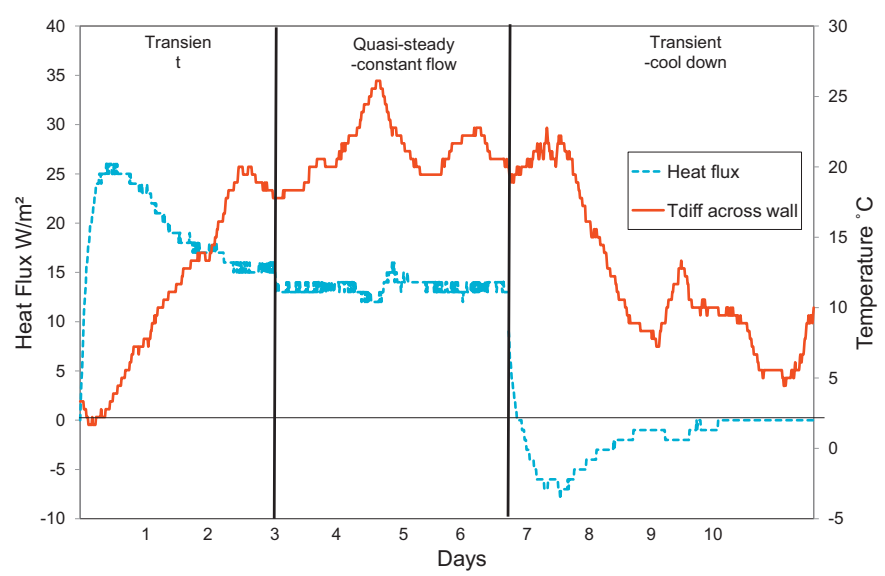

Fig. 11. Heat flux through the insulated wall during heating up, quasi-steady heat loss and cooling down phases.

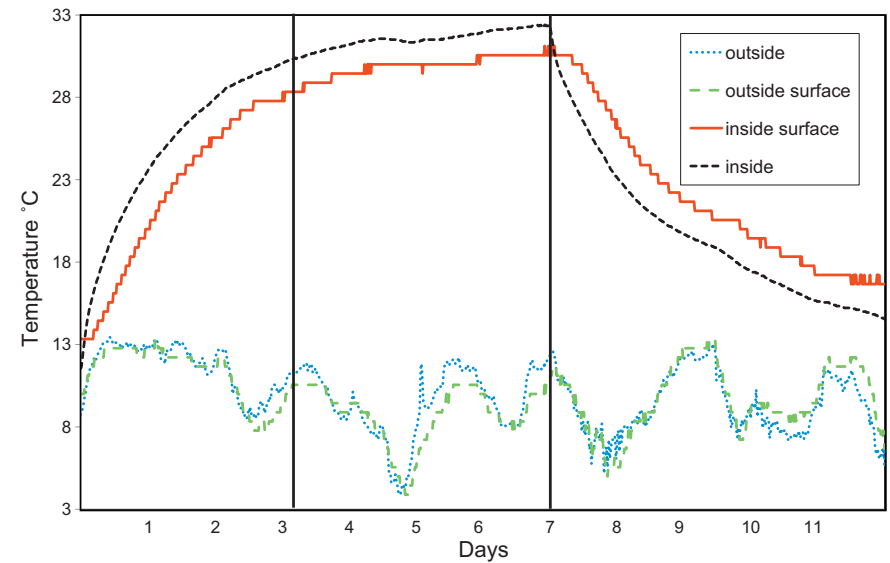

Fig. 12. Surface and air temperatures around the insulated wall.

overvalue the actual working resistance of the wall particularly in the post-case. Using the averaging method outlined in ISO 9869 [34], the achievable thermal resistance value of the wall rose by $1.232 \mathrm{~m}^{2} \mathrm{~K} / \mathrm{W}$. However, the stated thermal resistance value for $100 \mathrm{~mm}$ of pumped insulation of this type is $3.125 \mathrm{~m}^{2} \mathrm{~K} / \mathrm{W}$ [40].

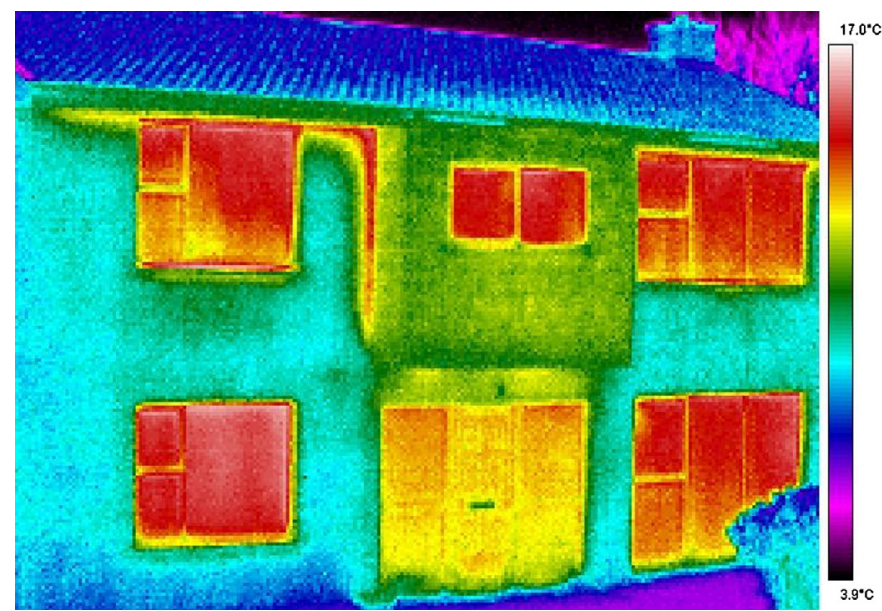

Fig. 13. Front face of building post-retrofit. 
Under idealised conditions using ISO 6946 the $R$-value of the wall should increase by $2.949 \mathrm{~m}^{2} \mathrm{~K} / \mathrm{W}$. Post-retrofit this measurement becomes comparatively much more erratic with a standard deviation of 0.189 . It is $461 \%$ higher than in the pre-case. This is the opposite of what happens to the heat flux which becomes much smoother. By examining equation 4 it is understandable how this may occur. In both cases the ambient weather conditions fluctuate and therefore the temperature difference across the wall is fluctuating. In the pre-retrofit case, the heat flux into the wall also fluctuates, increasing when the temperature difference is high, and decreasing when it is low resulting in a consistent $R$-value. But in the post-retrofit case, the heat flux into the wall is no longer as influenced by these external conditions, remaining steady while the temperature difference fluctuates. A varying numerator and a constant denominator results in a fluctuating $R$-value. The implication is that under dynamic thermal loading the post-retrofit wall thermal impedance must include a capacitance component and the calculated $R$-value, which reflects steady state behaviour, is an incorrect metric to gauge the wall thermal performance.

During the cooling down phase, after the heat is turned off, both pre- and post-retrofit wall heat flux patterns looked similar. However, two significant findings were observed. In the post-retrofit case, the heat flow into the wall returned to zero within $3 \mathrm{~h} 44 \mathrm{~min}$, in the pre-retrofit condition, the wall continued to draw heat from the internal space over the following days, never fully returning to zero over the recorded period. Furthermore, for the post-retrofit case, and adding to the argument earlier in this section that heat is being stored in the internal block layer, heat is then seen to flow back into the internal space from the wall, recorded as a negative heat flux in Fig. 11. Indeed the area difference between steady state heat flux and the heating up curve, and the area difference between the steady state cold (i.e. zero flux) and heat return to the room show a similar pattern. The heat built up and stored in the wall in phase one was $1813.46 \mathrm{~kJ} / \mathrm{m}^{2}, 826.20 \mathrm{~kJ} / \mathrm{m}^{2}$ of which was returned to the inner space during phase three. It is essential to note here that the wall and internal air temperature were significantly higher at $17.2^{\circ} \mathrm{C}$ and $14.5^{\circ} \mathrm{C}$ respectively at the completion of the experiment (compared to $13.3^{\circ} \mathrm{C}$ and $11.6^{\circ} \mathrm{C}$ at the beginning) and so it can be proposed that if internal temperatures were forced to drop to the original level, that all stored heat in the wall would be returned to the inner space. Because of this returned heat, total heat lost through the walls over a 12 day period (including a 7 day period of heating at maximum power) reduced from $22,806.00 \mathrm{~kJ} / \mathrm{m}^{2}$ to $8937.90 \mathrm{~kJ} / \mathrm{m}^{2}$, i.e. a $60.8 \%$ reduction in total heat lost through the walls at that point for the same heat energy input.

\subsubsection{Ceiling}

Similar to the wall's behaviour, the time it took for the ceiling to reach quasi steady heat loss for phase one increased from approximately $12 \mathrm{~h}$ to $21 \mathrm{~h}$ (see Figs. 7 and 14). However, unlike the wall, evidence of significant heat storage is not present as both pre- and post-retrofit ceilings reach a high point of heat flux and remain fluctuating about this point. This is attributed to the low thermal mass and therefore low heat capacity of the ceiling. Here the longer time in the post-retrofit ceiling is attributed to lowered influence of the cold attic space on the heat transfer. Heat transfer through the ceiling reduces as there is now a layer of insulation between the cold space and the ceiling resulting in less heat being transferred and thus a longer time to reach steady heat loss.

Visually the ceiling shows a significant change in a number of areas where originally there was no insulation installed. Fig. 16 displays the same area of ceiling as Fig. 10 in the main bedroom. There is a visible reduction in heat loss to the attic in this area. Similar areas were identified in a number of locations. The internal surface

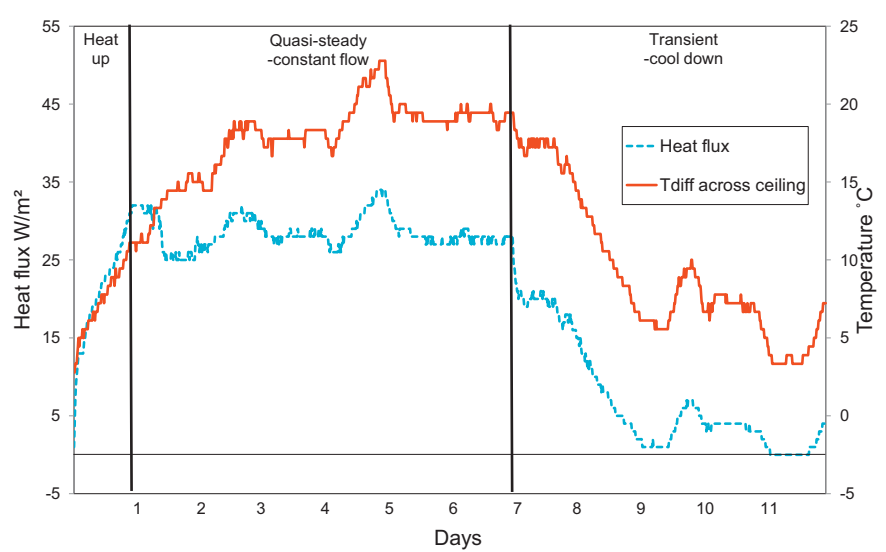

Fig. 14. Heat flux through the insulated ceiling during heating up, quasi-steady heat loss and cooling down phases.

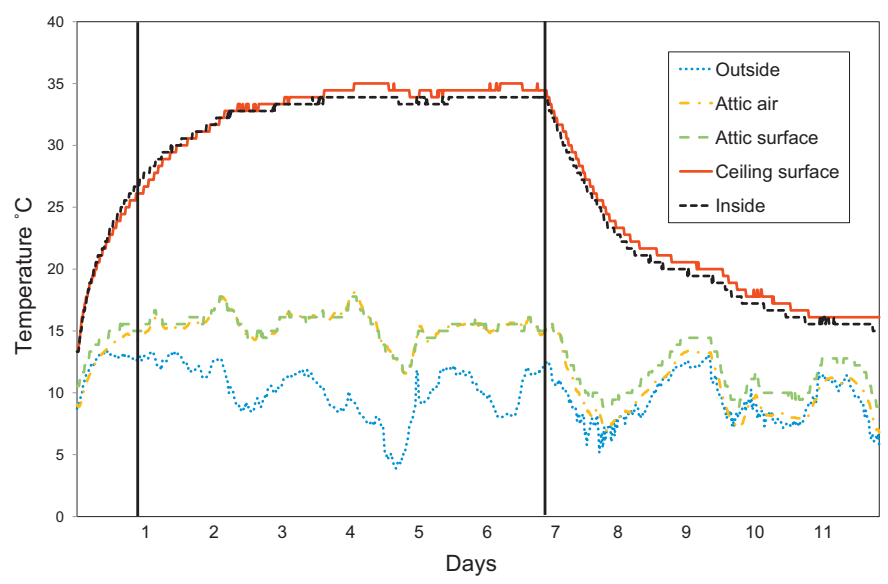

Fig. 15. Surface and air temperatures around the insulated ceiling.

temperature also changed to closely follow the internal air temperature (Fig. 8 changing to Fig. 15) which reflects this reduction in heat loss through the ceiling.

During phase two, quasi steady heat flow, the ceiling showed an average reduction in heat flux of $35.5 \%$ to $28.5 \mathrm{~W} / \mathrm{m}^{2}$ over an integer multiple of $24 \mathrm{~h}$ for a constant heat energy input and a moderate reduction in standard deviation of 1.81 to 2.0 . The predicted reduction in heat loss using the calculation method was much higher at

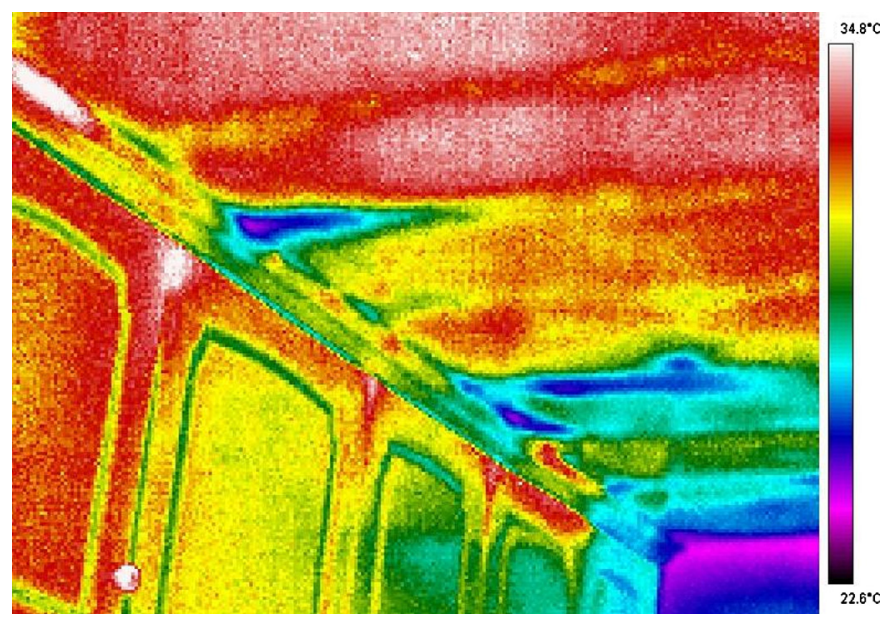

Fig. 16. Area of ceiling above main bedroom once insulation has been fitted. 


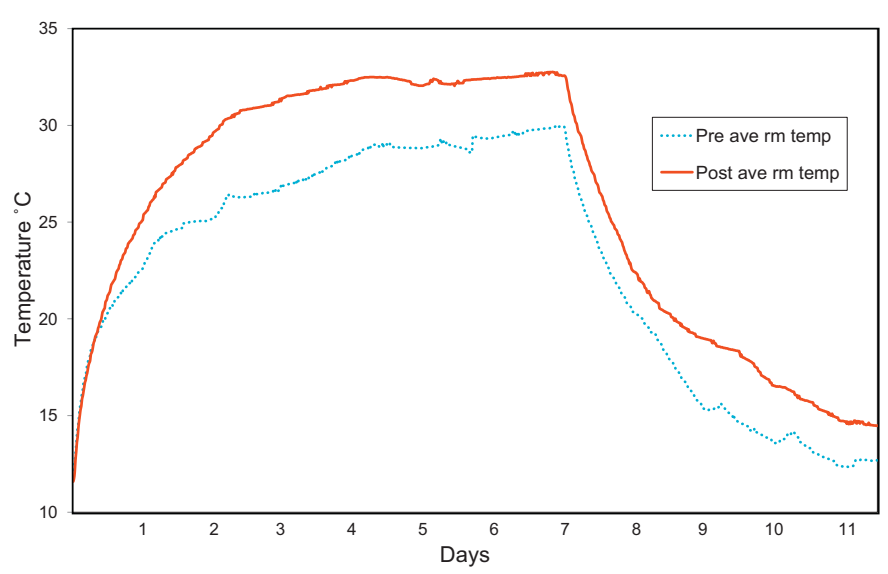

Fig. 17. Average room and hall temperatures over the test periods.

83.3\% reduction using air temperatures encountered in situ. Similar to the wall case, thermal resistance of the ceiling rose from $0.082 \mathrm{~m}^{2} \mathrm{~K} / \mathrm{W}$ to $0.682 \mathrm{~m}^{2} \mathrm{~K} / \mathrm{W}$ with a standard deviation of 0.027 . Again, while this is a significant increase, it remains below the calculated change due to insulation which was predicted to increase $R$ by $2.33 \mathrm{~m}^{2} \mathrm{~K} / \mathrm{W}$ [41]. Once more the increase in temperature difference across the body and decrease in heat flux as shown in Fig. 14 compared to previous Fig. 7 resulted in an increase in dynamic $R$-values. Fig. 16 displays that the internal air and surface temperatures are very much in synch as is the case in the attic. This is due to the block to heat flow between the two spaces due to the installed insulation. Furthermore the fluctuating pattern of the external temperature is no longer identifiable internally.

For the cooling down phase shown in Figs. 7 and 14, while the heat flux to the ceiling returns to zero more quickly post retrofit, no stored heat is returned from it to the internal space and heat flux remains at zero or positive after this point. While $R$-value has increased, the overall heat capacity of the system has not significantly changed as the insulation has a low heat capacity. This further explains the difference in behaviour, and the difference in the change in behaviour due to insulation, between the wall and ceiling.

\subsubsection{Damping/moderating and heat retention}

The reduction in heat loss through the ceiling and walls resulted in an overall increase in indoor temperature of $3.66^{\circ} \mathrm{C}$ on average during the 5 day period of heating after the initial day of heating (Fig. 17). Most rooms increased by over $4^{\circ} \mathrm{C}$, with the south-west facing living room increasing by $4.83^{\circ} \mathrm{C}$. The time it took for the internal temperature to increase by $8^{\circ} \mathrm{C}$ to roughly $20^{\circ} \mathrm{C}$ in phase one reduced from $11 \mathrm{~h} 15 \mathrm{~min}$ to $8 \mathrm{~h} 45 \mathrm{~min}$ for average internal temperature. The time it took for individual rooms to reach approximately $20^{\circ} \mathrm{C}$ was even more greatly reduced, the highest of which was a $5 \mathrm{~h}$ reduction in the living room. As the heat input and fuel consumption was the same in both pre- and post-cases, the fuel efficiency of the building increased by $0.41 /{ }^{\circ} \mathrm{C}$ above ambient/day. Furthermore, the household temperatures became more uniform throughout the building. The temperature difference between the living room and the warmest bedroom reduced from $4.7^{\circ} \mathrm{C}$ to just $1.7^{\circ} \mathrm{C}$ after retrofit.

It was observed that the room temperature profiles became smoother reducing in standard deviation by $18 \%$ and steadied out much more quickly when insulation was present as external environmental fluctuations became less influential. As seen in Fig. 18, while external weather fluctuations remain similarly high pre- and post-retrofit, the fluctuations in temperature of the internal surface of the wall drops significantly post-retrofit. A similar reduction in

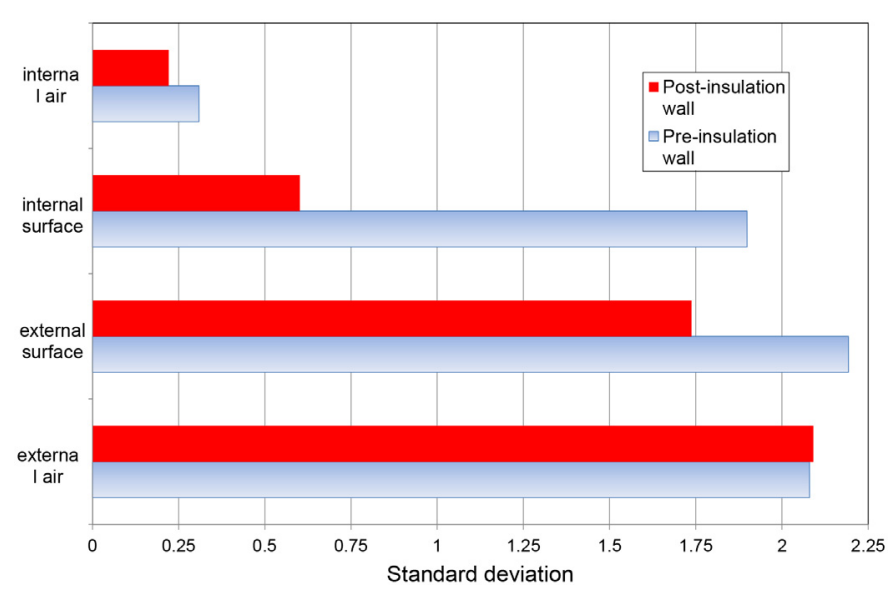

Fig. 18. Standard deviation of wall layers pre- and post-insulation fitting.

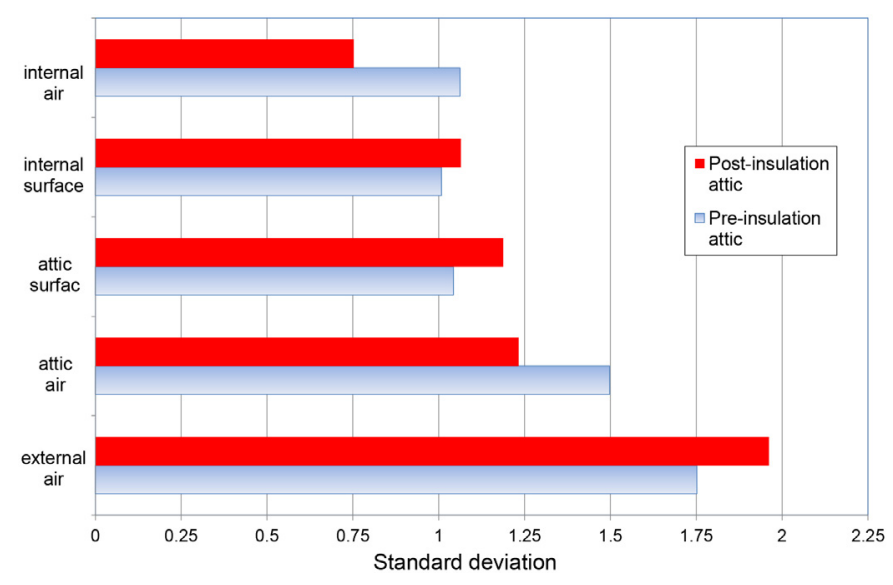

Fig. 19. Standard deviation of attic layers pre- and post-insulation fitting.

internal fluctuations can be seen in the ceiling system temperatures of Fig. 19. However, in the case of the attic, due to the lower thermal mass available, there is no observable pattern of ever reducing standard deviation in the layers. Indeed fluctuations remain high at each layer, even surpassing the pre-insulation scenario in some cases.

\subsection{Discussion and conclusion}

While simulations are sometimes used to analyse wall and other building envelope components, this is much less frequently analysed in situ, leading to a limited understanding of how the building envelope behaves under different conditions and practical circumstances. This investigation specifically focused on the value added to the property by wrapping it in common types of insulation. The value determined included the internal temperature achievable, the fuel usage per degree increase in internal temperatures, the heat storage behaviour of the walls and ceiling and their ability to resist the flow of heat out of the building as well as the damping effect of its thermal mass.

Though it is understood that it is very difficult to recreate ideal conditions in situ for measuring the $R$-value of building envelopes, it was found that the improvement in dynamic $R$-value to the property's ceiling and wall were respectively $75 \%$ and $60 \%$ lower than the predicted rise in $R$-value using the calculation method. These predicted $R$-values then overestimated the reduction in heat losses through the ceiling by nearly $50 \%$ and through the wall by nearly $20 \%$. This paper concludes that not only are calculated $R$-values 
unable to precisely reflect this case study building's reduction in heat loss through its walls and ceiling due to retrofitting insulation, but that these values do not reflect the change in behaviour of the entire system. This calculation method does not take into account the benefit of the thermal mass of the wall layers on the wall's behaviour. Building walls can store heat acting as a passive source and sink of heating energy. This is most useful during cooling down of the internal environment when the heat stored in the wall can be released to the cooler internal space. This behaviour was only observed once cavity insulation was introduced with heat stored in the inner leaf of the walls in heating up the property partially returned back to it when the heating was turned off. This meant that not only were average heat losses for the same heat energy supply reduced, but the total heat lost over the measurement period was even further reduced when the returned heat from this inner layer is included. In use, this results in lengthening the periods between artificial heating use, lowering energy use and carbon dioxide emissions. Moreover, internal fluctuations in temperature were damped and there was a notable reduction in thermal bridging observed using thermal imaging especially at joints and positions of radiators.

Further studies need to be conducted on other buildings and retrofit types so that the correct measures can be prescribed to achieve the most efficient outcome. While general findings in this paper reflect and add merit to simulations, it would be beneficial to run simulations parallel to specific cases in order to quantify more precisely the accuracy of computer models in predicting thermal changes due to retrofit. Building in-use data will also help to assess the real saving potential of the retrofit grant scheme and its contribution to national energy saving targets. This can then highlight where future government subsidies should be focused.

\section{References}

[1] Council of the European Union, Brussels, 8/9 March 2007 - Presidency Conclusions, 7224/1/07 REV 1 CONCL 1, Brussels, 2007.

[2] Commission of the European Communities, Communication from the Commission - energy efficiency: delivering the $20 \%$ target, in: Commission of the European Communities (Ed.) COM(2008) 772 final, 2008

[3] Sustainable Energy Authority of Ireland, Better Energy Homes Scheme statistics Web, 2012. Available from: http://www.seai.ie/Grants/Better_energy_ homes/Better_Energy_Statistics/

[4] P. Baker, $U$-values and traditional buildings, In situ measurements and their comparisons to calculated values, Technical Paper 10, Glasgow Caledonian University, Glasgow, 2011.

[5] F. Domínguez-Muñoz, B. Anderson, J.M. Cejudo-López, A. Carrillo-Andrés, Uncertainty in the thermal conductivity of insulation materials, Energy and Buildings 42 (11) (2010) 2159-2168.

[6] R.C. Valore Jr., Calculation of $U$-values of hollow concrete masonry, Concrete International 2 (2) (1980) 40-63.

[7] F. Björk, T. Enochsson, Properties of thermal insulation materials during extreme environment changes, Construction and Building Materials 23 (6) (2009) 2189-2195.

[8] F. Ochs, H. Müller-Steinhagen, Temperature and moisture dependence of the thermal conductivity of insulation materials, in: NATO Advanced Study Institute on Thermal Energy Storage for Sustainable Energy Consumption, Izmir, Casme, 2005.

[9] B.R. Anderson, The thermal resistance of airspaces in building constructions, Building and Environment 16 (1) (1981) 35-39.

[10] H. Hens, A. Janssens, W. Depraetere, J. Carmeliet, J. Lecompte, Brick cavity walls: a performance analysis based on measurements and simulations, Journal of Building Physics 31 (2) (2007) 95-124.

[11] D.P. Aviram, A.N. Fried, J.J. Roberts, Thermal properties of a variable cavity wall, Building and Environment 36 (9) (2001) 1057-1072.

[12] S.H. Hong, T. Oreszczyn, I. Ridley, The impact of energy efficient refurbishment on the space heating fuel consumption in English dwellings, Energy and Buildings 38 (10) (2006) 1171-1181.
[13] D.T. Harrje, R.A. Grot, Instrumentation for monitoring energy usage in buildings at Twin Rivers, Energy and Buildings 1 (3) (1978) 293-299.

[14] F.W. Sinden, A two-thirds reduction in the space heat requirement of a Twin Rivers townhouse, Energy and Buildings 1 (3) (1978) 243-260.

[15] H. Hens, Energy efficient retrofit of an end of the row house: Confronting predictions with long-term measurements, Energy and Buildings 42 (10) (2010) 1939-1947.

[16] G. Milne, B. Boardman, Making cold homes warmer: the effect of energy efficiency improvements in low-income homes. A report to the Energy Action Grants Agency Charitable Trust, Energy Policy 28 (6-7) (2000) 411-424.

[17] S. Doran, DETR Framework Project Report: Field investigations of the thermal performance of construction elements as built, Building Research Establishment Client Report No. 78132, Glasgow, 2000.

[18] J. Wingfield, Technical Note: Measurement of Heat Loss via Thermal Bypasses in Separating Party Wall Cavities, Leeds Metropolitan University, Leeds, 2010.

[19] P. Baker, In situ $U$-value measurements in traditional buildings - preliminary results, Technical Paper 2, Historic Scotland Technical Conservation Group, Glasgow, 2008.

[20] S. Lorente, M. Petit, R. Javelas, The effects of temperature conditions on the thermal resistance of walls made with different shapes vertical hollow bricks, Energy and Buildings 28 (3) (1998) 237-240.

[21] G. Desogus, S. Mura, R. Ricciu, Comparing different approaches to in situ measurement of building components thermal resistance, Energy and Buildings 43 (10) (2011) 2613-2620.

[22] M.A. Medina, Validation and simulations of a quasi-steady state heat balance model of residential walls, Mathematical and Computer Modelling 30 (7-8) (1999) 93-102.

[23] K.L. Wong, T.L. Hsien, M.C. Hsiao, W.L. Chen, K.C. Lin, The inaccuracy of conventional one-dimensional parallel thermal resistance circuit model for two-dimensional composite walls, Energy Conversion and Management 49 (10) (2008) 2554-2562.

[24] P.T. Tsilingiris, On the thermal time constant of structural walls, Applied Thermal Engineering 24 (5-6) (2004) 743-757.

[25] P.T. Tsilingiris, The influence of heat capacity and its spatial distribution on the transient wall thermal behavior under the effect of harmonically time-varying driving forces, Building and Environment 41 (5) (2006) 590-601.

[26] N. Lukić, The transient house heating condition-the daily changes of the building envelope response factor (BER), Renewable Energy 30 (4) (2005) 537-549.

[27] E. Kossecka, J. Kosny, Influence of insulation configuration on heating and cooling loads in a continuously used building, Energy and Buildings 34 (4) (2002) 321-331.

[28] BS EN ISO 8990:1996, Thermal Insulation - Determination of Steady-state Thermal Transmission Properties - Calibrated and Gaurded Hot Box, 1996.

[29] BS EN 1934:1998, Thermal Performance of Buildings - Determination of Thermal Resistance by Hot Box Method Using Heat Flow Meter, 1998.

[30] K. Ghazi Wakili, C. Tanner, $U$-value of a dried wall made of perforated porous clay bricks: hot box measurement versus numerical analysis, Energy and Buildings 35 (7) (2003) 675-680.

[31] Department of the Environment Heritage and Local Government, in: Government (Ed.), Building Regulations 2007, Technical Guidance Document L: Conservation of Fuel and Energy - Dwellings, The Stationary Office, Dublin, 2007.

[32] CIBSE, Guide A: Environmental Design, CIBSE Publications, London, 2007.

[33] P. Baker, In Situ $U$-value Measurement in Traditional Buildings, For Historic Scotland, Glasgow Caledonian University, Glasgow, 2008.

[34] ISO 9869:1994, Thermal Insulation - Building Elements - In Situ Measurement of Thermal Resistance and Thermal Transmittance (ISO 9869:1994), Geneva, 1994.

[35] S.A. Al-Sanea, M.F. Zedan, S.N. Al-Hussain, Effect of thermal mass on performance of insulated building walls and the concept of energy savings potential, Applied Energy 89 (1) (2012) 430-442.

[36] P.T. Tsilingiris, Parametric space distribution effects of wall heat capacity and thermal resistance on the dynamic thermal behavior of walls and structures, Energy and Buildings 38 (10) (2006) 1200-1211.

[37] myWeather2.com, Donegal Climate History, in Scotland.

[38] W. Eichhammer, B. Schlomann, A Comparison of Thermal Building Regulations in the European Union, MURE case study No.1, MURE Database (Mésures d'Utilisation Rationelle de l'Energie), Karlruhe, 1998 (www.mure2.com/ Casestud.htm).

[39] ISO 6946:2007, Building Components and Building Elements - Thermal Resistance and Thermal Transmittance - Calculation Method (ISO 6946:2007), NSAI, Dublin, 2007.

[40] The Irish Agrément Board, Certainfill Bonded Bead Cavity Wall Insulation System in: Certificate No. 06/0168, 2002.

[41] The Irish Agrément Board, Saint-Gobain, Isover: Loft Insulation Products, Spacesaver, Spacesaver Plus and General Purpose Roll Providing Thermal Insulation in Domestic Loft Spaces, 2008. 